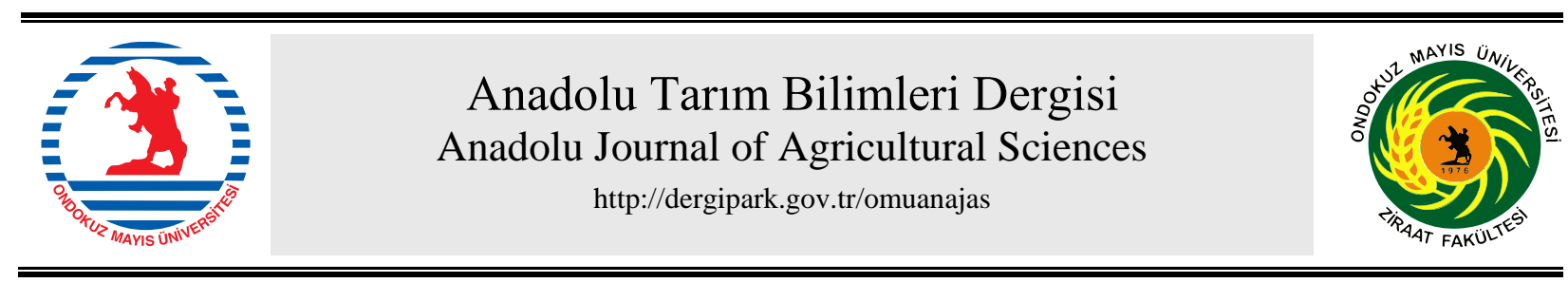

Araştırma/Research

Anadolu Tarım Bilim. Derg./Anadolu J Agr Sci, 36 (2021)

ISSN: 1308-8750 (Print) 1308-8769 (Online)

doi: 10.7161/omuanajas.785167

\title{
In Vitro Koşullarda Farklı Glisin Konsantrasyonlarının Çileklerde Tuzluluk Stresi Üzerine Etkileri
}

\author{
Eda Elif Yavuzlar ${ }^{\mathrm{a}, \mathrm{b}^{*}}$, ๑ Serra Karadal ${ }^{\mathrm{a}}$, ๑ Nafiye Adak ${ }^{\mathrm{b}}$ \\ *Akdeniz Üniversitesi, Ziraat Fakültesi, Bahçe Bitkileri Bölümü, Antalya, Türkiye \\ *Sorumlu yazar/corresponding author: edaelifyavuzlar@gmail.com
}

Geliş/Received 25/08/2020 Kabul/Accepted 24/05/2021

\begin{abstract}
ÖZET
Abiyotik stres faktörleri, bitki büyüme ve gelişmesi ile verim ve kaliteyi önemli derecede etkilemektedir. $\mathrm{Bu}$ nedenle dışarıdan uygulanan bazı preparatların strese tolerans derecelerinin belirlenmesi yetiştiricilikte önem arz etmektedir. Bu amaçla yapılan çalışmada, in vitro koşullarda farklı tuzluluk düzeylerinde $(\% 0,0.4,0.8 \mathrm{NaCl})$, farklı glisin konsantrasyonlarının $(0,1.0,2.0,4.0$ $\mathrm{mg} \cdot \mathrm{l}^{-1}$ ) eksplantlarda sürgün gelişimi üzerine etkileri incelenmiştir. Araştırma sonucunda, tuzluluk konsantrasyonlarının artışına bağlı olarak, sürgün sayısı, sürgün boyu, sürgün yaş ve kuru ağırlı̆̆ önemli derecede azalmıştır. Buna karşın gerek orta (\% 0.4$)$ ve gerekse yüksek (\% 0.8$) \mathrm{NaCl}$ düzeylerinde denenen tüm glisin konsantrasyonları eksplant sürgün gelişimi üzerine olumlu etki göstermiştir. Özellikle $2 \mathrm{mg} \cdot \mathrm{l}^{-1}$ ve $4 \mathrm{mg} \cdot \mathrm{l}^{-1}$ glisin konsantrasyonları tüm tuzluluk şartlarında sürgün gelişimini teşvik etmiştir. Ayrıca glisin konsantrasyonlarının artışına bağlı olarak sürgün sayısı, sürgün yaş ve kuru ağırlığı artarken, sürgün boyu azalmıştır. Araştırma sonuçları, in vitro koşullarda glisin uygulamalarının tuzluluk stresinin zararını azaltıcı etkide bulunduğunu göstermiştir.
\end{abstract}

\section{Effects of Different Glycine Concentrations on Salinity Stress in Strawberries under In Vitro Conditions}

\begin{abstract}
Abiotic stress factors significantly affect plant growth and development, yield and quality. Therefore, effects of some exogenous preparations for growing is considerable. In this study, the effects of different glycine concentrations $\left(0,1.0,2.0,4.0 \mathrm{mg} \mathrm{l}^{-1}\right)$ on shoot development at different salinity levels $(0,0.4,0.8 \mathrm{NaCl})$ under in vitro conditions were investigated.The result of the study, shoot number, shoot length and shoot fresh and dry weight decreased depend on increasing salinity concentrations under in vitro conditions. However, all the tested glycine concentrations showed a positive effect on shoot development in both medium $(0.4 \%)$ and high $(0.8 \%) \mathrm{NaCl}$ levels. In particular, $2 \mathrm{mg} \mathrm{l}^{-1}$ and $4 \mathrm{mg} \mathrm{l}^{-1}$ glycine concentrations induced shoot growth in all salinity levels. Furthermore, depend on increasing glycine concentrations, shoot number, shoot fresh and dry weight were increased, but shoot length was decreased. In conclusion, glycine treatments have shown that the ameliorate the harm of salinity stress under in vitro conditions.
\end{abstract}

Anahtar Sözcükler: Abiyotik stres Çoğalma aşaması Doku kültürü Sürgün sayısı
Keywords: Abiotic stress Multiplication phase Shoot number Tissue culture 


\section{Giriş}

Kuraklık, tuzluluk, düşük ve yüksek sıcaklık faktörleri gibi çevresel etkenlere dayalı abiyotik stres faktörleri tüm dünya ülkelerinde sıkça yaşanan iklim değişikliklerinin bir sonucudur. Günümüzde dünya tarım alanlarının yaklaşık olarak \%45'i kuraklık stresine maruz kalmakta ve bu kuraklıkla birlikte tarım alanlarının \%6'sında tuzluluk meydana gelmektedir (Epstein ve ark., 1980; Kuşvuran, 2010). Toprakların verimliliğini olumsuz yönde etkileyen ve geniş alanların tarım dışı kalmasına neden olan tuz stresi, bugün tarımsal üretim alanlarında önemli bir sorun haline gelmiştir. Tarımsal anlamda önemli zararlar teşkil eden bu stres faktörü, bitki morfolojisi ve anatomisini etkilerken, büyüme ve gelişmeyi de sınırlandırmaktadır (Levitt, 1980; Awang ve ark., 1993; D’Anna ve ark., 2003; Keutgen ve Keutgen, 2003; Turhan ve Eriş, 2007; Büyük ve ark., 2012). Özellikle tuz stresinde bitki besin elementleri alınımları azalmakta ve hücrelerde iyonik dengesizlikler gerçekleşmektedir. Potasyum, kalsiyum ve sodyum gibi elementlerin bitkiler tarafından alınımları etkilenirken, bitki kuru ağırlığı, $\mathrm{K}, \mathrm{Na}$ ve $\mathrm{Ca}$ oranları da bitkilerde stres seviyelerinin göstergesi olarak da kullanılmaktadır (Torun ve ark., 2007). Ayrıca meydana gelen oksidatif stres hücrenin metabolik faaliyetlerini de etkileyerek antioksidan enzim aktivitelerini de harekete geçirebilmektedir (Greenway ve Munns, 1980; Adak ve ark., 2018). Bu konuda yapılan bir çalışmada Turhan ve Eriş (2007), sera koşullarında yetiştirilen Camarosa ve Chandler çilek çeşidi bitkilerinde, 0 , 8.5, 17.0 ve $34.0 \mathrm{mM}$ $\mathrm{NaCl}$ uygulamalarının yaprak alanı, yaprak sayısı, yaprak, gövde ve kök yaş ağırlığını azalttığı, yaprak sıcaklığını artırdığı, stoma iletkenliğini ve transpirasyon oranını da etkilediğini bildirmişlerdir. Ayrıca Aktaş ve Kılıç (2013) in vivo şartlarda soya filizi yetiştiriciliği üzerine 25 ve $50 \mathrm{mM} \mathrm{NaCl}$ dozlarında tuzluluğun sürgün ve kök uzunluğu ile sürgün ve kök taze ağırlığı üzerine etkili olduğu ve özellikle tuzluluğun sürgün-kök uzunluğu ve sürgün-kök taze ağırlığında azalmalara neden olduğu saptanmıştır.

Çilek, tuzluluğa hassas bitki kategorisinde olup, tür ve çeşitler arasında dayanım bakımından varyasyonlar bulunmaktadır (Hoffman, 1981; Martinez ve Alvarez, 1997; D’Anna ve ark., 2003; Saied ve ark., 2005; Keutgen ve Pawelzik, 2007; Yılmaz ve Kina, 2008). Nitekim bu konuda Yavuzlar ve Adak (2019) oktoploid türlerin, tetraploid ve diploid türlere göre tuzluluk stresine daha toleranslı olduğunu belirtmişlerdir. Ayrıca Torun ve ark. (2007), doku kültürü yoluyla çilek genotiplerinin yüksek $\mathrm{NaCl}$ konsantrasyonlarına tepkilerinin, hızlı ve etkili bir şekilde belirlenebileceğini belirtmişlerdir. Yapılan diğer bir çalışmada Yılmaz ve Kina (2008), 500, 1000 ve $1500 \mathrm{mg} \cdot \mathrm{l}^{-1}$ tuz uygulanan Hoagland besin çözeltisi ile sulanan Kabarla ve Gloria çilek çeşitlerinde, tuz konsantrasyonun artışına bağlı olarak vejetatif büyümenin kısıtlandığı ve yaprak yüzey alanının azaldığı gözlenmiştir. Denemede ayrıca yüksek doz uygulamalarında yaprak kuru ağırlığının azalmasına karşın, düşük doz uygulamalarında yaprak kuru ağırlığının arttığı belirlenmiştir. Diğer bir çalışmada ise Zhao ve ark. (2017) "Sweet Charlie" ve "Benihoppe" çilek çeşitlerinin kullanıldığı in vitro çalışmada, çeşitlerin tuz toleransı ve alkali tolerans endeksleri belirlenmiştir.

Ülkemizde ve tüm dünya ülkelerinde iklim değişiklikleri ile birlikte artan tuzluluk stresinin tarımsal verimliliği etkilemesi kaçınılmazdır. Bu nedenle son yıllarda tuzluluk ve kuraklık gibi abiyotik stres faktörlerine toleranslı tür ve çeşitlerin belirlenmesi, ıslahı ve toleransı artırıcı pratik uygulamalar üzerine ayrıntılı çalışmalar bahçe bitkileri alanında önemli araştırma alanlarını teşkil etmektedir (Üzal ve Yıldız, 2014). Bu nedenlerle planlanan bu çalışmanın amacı, in vitro şartlarda glisin aminoasitinin kullanımının eksplantlarda büyüme, gelişme ve çoğalma kapasitesi üzerine etkilerini belirlemek ve sonuçların in vivo şartlara uygulanabilirliği konusunda öneriler yapmaktır.

\section{Materyal ve Yöntem}

Araştırma, 2016-2017 yılları arasında yürütülmüş olup, deneme materyali olarak Benicia çilek çeşidinin sürgün uçları kullanılmışıır. Sürgün uçları mayıs ayı sonunda fidelik parsellerinden sökülmüş, temizlenmiş ve laboratuvar şartlarında öncelikle yüzey sterilizasyonuna tabi tutulmuştur. Yüzey sterilizasyonu ve meristem izolasyonu Yavuzlar ve Adak (2019)'a göre gerçekleştirilmiş olup, besi ortamı olarak \%3 sakkaroz ve \% 0.7 Difco Bacto agar içeren Murashige ve Skoog (MS) ortamı kullanılmıştır. Meristem büyüme ve gelişme aşamasında besi ortamına $1 \mathrm{mg} \cdot \mathrm{l}^{-1}$ BAP ve $1 \mathrm{mg} \cdot \mathrm{l}^{-1} \mathrm{IAA}$ ilavesi gerçekleştirilerek, dört hafta boyunca meristemlerin büyüme ve gelişmesi sağlanmıştır. Daha sonra gelişen eksplantlar farklı tuzluluk (kontrol, \% $0.4 \mathrm{NaCl}, \% 0.8 \mathrm{NaCl}$ ) ve farklı glisin konsantrasyonları (kontrol, $1 \mathrm{mg} \cdot \mathrm{l}^{-1}, 2 \mathrm{mg} \cdot \mathrm{l}^{-1}, 4 \mathrm{mg} \cdot \mathrm{l}^{-1}$ ) içeren besi ortamlarında kültüre alınarak eksplantların ikinci alt kültür sonunda sürgün çoğalma kapasitesi ve sürgünlerin gelişme durumları gözlenmiştir. Denemede kültür odası çevresel şartları, sıcaklık $25^{\circ} \mathrm{C} \pm 1^{\circ} \mathrm{C}$, 1şık yoğunluğu $3000 \mu \mathrm{mol} \mathrm{s} \mathrm{s}^{-1} \mathrm{~m}^{-2}$, fotoperiyot 16 saat aydınlık, 8 saat karanlık olarak düzenlenmiştir.

Araştırmada, eksplant başına düşen sürgün sayısı (adet·eksplant-1), sürgün boyu $(\mathrm{cm})$, sürgün yaş ve kuru ağırlı̆̆ 1 (g) değerleri de incelenmiştir. Deneme üç tekerrürlü ve her tekerrürde 5 eksplant olacak şekilde tesadüf bloklarında faktöriyel deneme desenine göre planlanmış ve ortalamalar LSD\%5’e göre karşılaştırılmıştır.

\section{Bulgular ve Tartışma}




\subsection{Sürgün sayısı (adet) ve sürgün boyu (cm)}

Benicia çilek çeşidinde, farklı tuzluluk düzeylerinde, glisin konsantrasyonlarının sürgün sayısı ve sürgün boyu üzerine etkileri Çizelge 1'de verilmiştir. Glisin konsantrasyonlarının eksplant başına düşen sürgün sayısı üzerine etkisi istatistiksel olarak önemli bulunmuştur. En düşük sürgün sayısı kontrol uygulamasında elde edilirken, denenen tüm glisin konsantrasyonlarında sürgün sayısı kontrole göre yüksek belirlenmiştir. Tuzluluk uygulamalarının eksplant başına düşen sürgün sayısı üzerine etkisi istatistiksel olarak önemli bulunmamıştır. Bu değerler uygulamalara göre değişmekle birlikte, 11.83 adet ile 12.83 adet arasında değişim göstermiştir. İnteraksiyon incelendiğinde, en yüksek sürgün sayısı 20.00 adet ile $\% 0.4 \mathrm{NaCl}$ x $2 \mathrm{mg} \cdot \mathrm{l}^{-1}$ glisin uygulamasında elde edilmiştir. Dolayısıyla denenen düşük tuzluluk şartlarında (\% $0.4 \mathrm{NaCl}) 2 \mathrm{mg} \mathrm{l}^{-1}$ glisin en yüksek sürgün sayısını verirken, daha yüksek tuzluluk şartlarında $(\% 0.8 \mathrm{NaCl})$ daha yüksek $\left(4 \mathrm{mg} \cdot \mathrm{l}^{-1}\right)$ glisin konsantrasyonunun sürgün sayısı üzerine olumlu etkileri olduğu belirlenmiştir.

In vitro eksplantlarda gözlenen sürgün boyları değerleri de Çizelge 1'de verilmiştir. Glisin konsantrasyonlarının sürgün boyu üzerine etkisi istatistiksel olarak önemli belirlenmiştir. En yüksek sürgün boyu $1 \mathrm{mg} \cdot \mathrm{l}^{-1} \mathrm{glisin}$ konsantrasyonunda (2.55 adet) belirlenirken, glisin konsantrasyonun artışına bağlı olarak sürgün boyu azalmıştır. Tuz konsantrasyonlarının sürgün boyu üzerine etkisi istatistiksel olarak önemli bulunmuştur (Çizelge 1). En yüksek sürgün boyu $3.00 \mathrm{~cm}$ ile kontrol uygulamasında belirlenirken, denenen tüm tuz konsantrasyonlarında kontrolden daha düşük sürgün boyu saptanmıştır. Glisin konsantrasyonları x tuz uygulamaları interaksiyonu bakımından da uygulamalar arasında istatistiksel olarak önemli farkl1lıklar bulunmuştur. En yüksek sürgün boyu stressiz şartlarda görülürken, tuz uygulamaları sürgün boyunu azaltmıştır. Nitekim en düşük sürgün boyu $\% 0.8 \mathrm{NaCl}$ x Kontrol interaksiyonunda belirlenmiştir $(0.33 \mathrm{~cm})$ (Çizelge 1).

Araştırma bulgularımız, gerek eksplant başına düşen sürgün sayısı ve gerekse sürgün boyu üzerine tuzluluk şartlarında denenen tüm glisin konsantrasyonlarının kontrole göre etkili olduğunu göstermiştir. Glisin konsantrasyonları sürgün sayısını artırırken, sürgün boyunu kısaltmıştır. Dolayısıyla glisinin kültür ortamına ek ilavesinin, in vitro şartlarda çoğalma üzerine etkili olduğu çalışmamızda tespit edilmiştir.

Çizelge 1. Benicia çilek çeşidinde, farklı tuzluluk düzeylerinde glisin konsantrasyonlarının sürgün sayısı ve sürgün boyu üzerine etkileri

Table 2. Effects of glycine concentrations on shoot number and length at different salinity levels in Benicia strawberry cultivar

\begin{tabular}{|c|c|c|c|c|}
\hline \multirow{3}{*}{ Glisin Konsantrasyonları $\left(\mathrm{mg} \cdot \mathrm{l}^{-1}\right)$} & \multicolumn{3}{|c|}{ Tuz Konsantrasyonları } & \multirow{3}{*}{$\begin{array}{c}\text { Glisin } \\
\begin{array}{c}\text { konsantrasyonları } \\
\text { ortalaması }\end{array}\end{array}$} \\
\hline & Kontrol & $\% 0.4 \mathrm{NaCl}$ & $\% 0.8 \mathrm{NaCl}$ & \\
\hline & \multicolumn{3}{|c|}{ Sürgün sayısı (adet eksplant ${ }^{-1}$ ) } & \\
\hline Kontrol & $12.33 \mathrm{CD}$ & $2.00 \mathrm{E}$ & $0.33 \mathrm{E}$ & $4.89 \mathrm{~b}$ \\
\hline 1 & $10.33 \mathrm{D}$ & $15.00 \mathrm{BCD}$ & $16.00 \mathrm{ABC}$ & 13.77 a \\
\hline 2 & $11.00 \mathrm{D}$ & $20.00 \mathrm{~A}$ & 14.33 BCD & 15.11 a \\
\hline 4 & $13.67 \mathrm{CD}$ & 14.33 BCD & $19.00 \mathrm{AB}$ & $15.67 \mathrm{a}$ \\
\hline Tuz konsantrasyonları ortalaması & 11.83 & 12.83 & 12.41 & \\
\hline \multicolumn{5}{|c|}{ LSD\%5 tuz kons.:ÖD; LSD\%5glisin kons.: 2.794; LSD\%5 tuz x glisin kons.: 4.840} \\
\hline \multicolumn{5}{|c|}{ Sürgün boyu $(\mathrm{cm})$} \\
\hline Kontrol & $4.00 \mathrm{~A}$ & $1.67 \mathrm{CD}$ & $0.33 \mathrm{D}$ & $2.00 \mathrm{ab}$ \\
\hline 1 & $3.33 \mathrm{AB}$ & $2.33 \mathrm{BC}$ & $2.00 \mathrm{BC}$ & 2.55 a \\
\hline 2 & $2.33 \mathrm{BC}$ & $2.00 \mathrm{BC}$ & $1.67 \mathrm{CD}$ & $2.00 \mathrm{ab}$ \\
\hline 4 & $2.33 \mathrm{BC}$ & 1.67 CD & $1.33 \mathrm{CD}$ & $1.78 \mathrm{~b}$ \\
\hline Tuz konsantrasyonları ortalaması & $3.00 \mathrm{a}$ & $1.92 \mathrm{~b}$ & $1.33 \mathrm{~b}$ & \\
\hline
\end{tabular}

* Aynı sütunda yer alan ve aynı harfle başlayan ortalamalar arasındaki farklılık istatistiksel olarak önemsizdir $(\mathrm{P}<0.05)$.

\subsection{Sürgün yaş ve kuru ağırlı̆̆l (g)}

Benicia çilek çeşidinde, farklı tuzluluk düzeylerinde glisin konsantrasyonlarının sürgün yaş ve kuru ağırlık üzerine etkileri Çizelge 2'de verilmiştir. Çizelgede görüldüğü gibi glisin konsantrasyonlarının, sürgün yaş ve kuru ağırlığına olan etkisi istatistiksel olarak önemli bulunmuştur. Sürgün yaş ağırlı̆̆ değerleri, denenen tüm glisin konsantrasyonlarında kontrole göre yüksek belirlenmiştir. En yüksek sürgün yaş ağırlığı $3.36 \mathrm{~g}$ ile $4 \mathrm{mg} \cdot 1^{-1} \mathrm{glisin}$ konsantrasyonunda belirlenmiştir. Tuzluluk uygulamalarının sürgün yaş ağırlı̆̆ üzerine etkisi de istatistiksel olarak önemli bulunmuştur. $\mathrm{Bu}$ değerler uygulamalara göre değişmekle birlikte $2.55 \mathrm{~g}$ ve $3.18 \mathrm{~g}$ arasında değişim göstermiştir. İnteraksiyon bakımından incelendiğinde, en yüksek sürgün yaş ağırlığ $3.61 \mathrm{~g}$ ile $\% 0.4 \mathrm{NaCl}$ x $4 \mathrm{mg} \cdot l^{-1}$ glisin uygulamasında elde edilmiştir. En düşük sürgün yaş ağırlı̆̆ da $0.86 \mathrm{~g}$ ile $\% 0.8 \mathrm{NaCl}$ x Kontrol uygulamasında belirlenmiştir (Çizelge 2). 
Farklı tuzluluk düzeylerindeki glisin konsantrasyonlarının sürgün kuru ağırlığı üzerine etkileri de Çizelge 2'de verilmiştir. Glisin konsantrasyonlarının sürgün kuru ağırlığı üzerine etkisi istatistiksel olarak önemli bulunmuştur. Nitekim en yüksek sürgün kuru ağırlığ 1 sirasıyla 4 ve $2 \mathrm{mg} \cdot \mathrm{l}^{-1}$ glisin konsantrasyonunda belirlenirken, glisin konsantrasyonun artışına bağlı olarak sürgün kuru ağırlığ 1 da artmıştır. Tuzluluk konsantrasyonlarının sürgün kuru ağırlığı üzerine etkisi istatistiksel olarak önemli bulunmuştur. En yüksek kuru ağırlık $0.16 \mathrm{~g}$ ile \% $0.4 \mathrm{NaCl}$ konsantrasyonunda, en düşük $0.12 \mathrm{~g}$ ile kontrol uygulamasında belirlenmiştir (Çizelge 2).

Çizelge 2. Benicia çilek çeşidinde, farklı tuzluluk düzeylerinde glisin konsantrasyonlarının sürgün yaş ve kuru ağırlık üzerine etkileri

Table 2. Effects of glycine concentrations on shoot fresh and dry weight at different salinity levels in Benicia strawberry cultivar

\begin{tabular}{|c|c|c|c|c|}
\hline \multirow{3}{*}{ Glisin Konsantrasyonları (mg l $\left.\mathbf{l}^{-1}\right)$} & \multicolumn{3}{|c|}{ Uygulamalar } & \multirow{3}{*}{$\begin{array}{c}\text { Glisin } \\
\begin{array}{c}\text { konsantrasyonları } \\
\text { ortalaması }\end{array}\end{array}$} \\
\hline & Kontrol & $\% 0.4 \mathrm{NaCl}$ & $\% 0.8 \mathrm{NaCl}$ & \\
\hline & \multicolumn{3}{|c|}{ Sürgün yaş ağırlığı (g) } & \\
\hline Kontrol & $2.59 \mathrm{~A}$ & $2.97 \mathrm{~A}$ & $0.86 \mathrm{~B}$ & $2.14 \mathrm{~b}$ \\
\hline 1 & $2.77 \mathrm{~A}$ & $3.03 \mathrm{~A}$ & $3.03 \mathrm{~A}$ & $2.94 \mathrm{a}$ \\
\hline 2 & $2.53 \mathrm{~A}$ & $3.12 \mathrm{~A}$ & $3.08 \mathrm{~A}$ & $2.91 \mathrm{a}$ \\
\hline 4 & $3.23 \mathrm{~A}$ & $3.61 \mathrm{~A}$ & $3.24 \mathrm{~A}$ & $3.36 \mathrm{a}$ \\
\hline Tuz konsantrasyonları ortalaması & $2.78 \mathrm{ab}$ & $3.18 \mathrm{a}$ & $2.55 \mathrm{~b}$ & \\
\hline \multicolumn{5}{|c|}{ LSD\%5 tuz kons.::0.517; LSD\%5 glisin kons.: 0.596; LSD\%5tuzx glisin kons.:1.401 } \\
\hline \multicolumn{5}{|c|}{ Sürgün kuru ağırlığı (g) } \\
\hline Kontrol & $0.12 \mathrm{AB}$ & $0.14 \mathrm{AB}$ & $0.06 \mathrm{~B}$ & 0.106 b \\
\hline 1 & $0.11 \mathrm{AB}$ & $0.19 \mathrm{~A}$ & $0.14 \mathrm{AB}$ & 0.150 ab \\
\hline 2 & $0.11 \mathrm{AB}$ & $0.16 \mathrm{AB}$ & $0.19 \mathrm{~A}$ & 0.156 a \\
\hline 4 & $0.13 \mathrm{AB}$ & $0.16 \mathrm{AB}$ & $0.18 \mathrm{~A}$ & 0.159 a \\
\hline Tuz konsantrasyonları ortalaması & 0.12 b & 0.16 a & 0.15 ab & \\
\hline
\end{tabular}

LSD\%5 tuz kons.:.0.041; LSD\%5glisin kons.: 0.047; LSD\%5tuz x glisin kons.:0.111

* Aynı sütunda yer alan ve aynı harfle başlayan ortalamalar arasındaki farklılık istatistiksel olarak önemsizdir $(\mathrm{P}<0.05)$.

Araştırmalarımız gerek sürgün yaş ağırlığ 1 ve gerekse sürgün kuru ağırlığ üzerine tuzluluk şartlarında denenen tüm glisin konsantrasyonlarının kontrole göre etkili olduğunu göstermiştir. Glisin konsantrasyonlarının sürgün yaş ağırlığı ve sürgün kuru ağırlığını artırdığı kaydedilmiştir.

Araştırma sonuçlarımız bir çok araştırma bulguları ile benzerlik göstermektedir. Nitekim Gerdakaneh ve ark. (2010) yaptıkları çalışmada, farklı sakkaroz koşullarında (\%3, 6, 9 ve 12) tolerans artırıcı amaçlı dışsal L-prolin uygulamalarının $(0,2.5,5$ ve $10 \mathrm{mM})$ ozmotik stres durumunda çilek kalluslarında önemli fizyolojik parametreleri etkilediğini bildirmişlerdir. Araştırıcılar, sakkaroz konsantrasyonun artışına bağlı olarak, kallus dokularında kuru ağırlıklar artarken, taze ağırlık miktarının azaldığını belirtmişlerdir. Bizim çalışmamızda ise yüksek tuzlulukta $(\% 0.8 \mathrm{NaCl})$ sürgün yaş ağırlı̆ğ kontrole göre azalmış, kuru ağırlığı ise artmıştır. Benzer olarak Turhan ve Eriş (2007) in vivo şartlarda, 8.5, 17.0 ve $34.0 \mathrm{mM} \mathrm{NaCl}$ uygulamalarının Camarosa ve Chandler çilek çeşidi bitkilerinde fizyolojik büyümeyi önemli derecede etkilediğini belirtmişlerdir. Nitekim denemede tuzlu koşullar, yaprak ve kök yaş ağırlığı, yaprak alanı ve yaprak sayısını azaltırken, Camarosa çeşidinde stoma iletkenliğini ve transpirasyon oranını düşürmüştür. Bir başka çalışmada Torun ve ark., (2007), dört farklı çilek genotipinin (2 TAB 4B, CFRA 1267, HM1 ve Scotts Creek) in vitro koşullarda değişik NaCl konsantrasyonlarına $(0,25,50,75$ ve $100 \mathrm{mM})$ tepkilerini araştırdıkları çalışmada, yüksek tuz konsantrasyonunun çoğaltma katsayısını azalttığı, kuru ağırlık yanında, kalsiyum ve sodyum konsantrasyonlarını da etkilediğini tespit etmişlerdir. Genotiplerin kuru ağırlıklarında, bir azalma gözlemlense de, bu azalma en düşük olarak HM1 genotipinde kaydedilmiştir. Yapılan diğer bir çalışmada Yılmaz ve Kina (2008) Hoagland besin çözeltisi ile sulanan Kabarla ve Gloria çilek çeşidi bitkilerinde, 500, 1000 ve $1500 \mathrm{mg} \cdot l^{-1}$ tuz uygulamalarının vejetatif büyümeyi engellediği, yüksek doz uygulamalarda kuru yaprak ağırlığı azalmasına rağmen, düşük doz uygulamalarda kuru yaprak ağırlığının arttığı belirtilmiştir (Yılmaz ve Kina, 2008). Yapılan diğer bir çalışmada Zhao ve ark. (2017), "Sweet Charlie" ve "Benihoppe" çilek çeşitlerinin kullanıldığı in vitro çalışmada, çeşitlerin tuz ve alkali tolerans endeksleri belirlenmiş ve her iki stres faktöründe in vitro köklenme kabiliyetinin sınırlandırılarak köklenme oranı, ortalama kök sayısı ve kök uzunluğunun azaldığı görülmüştür.

\section{Sonuç}

Araştırma sonucunda, in vitro koşullarda tuzluluk stresi semptomlarının hızlı ve etkin bir şekilde görülebileceği belirlenmiş ve in vitro Murashige ve Skoog (1962) ortamına ilave glisin konsantrasyonlarının, eksplantlarda tuzluluk 
stresini azaltıcı etkide bulunduğu saptanmıştır. Özellikle $2 \mathrm{mg} \cdot{ }^{1-1}$ ve $4 \mathrm{mg} \cdot \mathrm{l}^{-1}$ glisin ilavesinin sürgün gelişimi üzerine pozitif etkileri olduğu belirlenmiştir.

\section{Kaynaklar}

Adak, N., Tozlu, I., Nasircilar, A.G., Ulukapi, K. 2018. In vitro assessment of drought tolerance responses in strawberry. Fresenius Environmental Bulletin, Volume 27, No. 12B, 9481-9486. https://www.prt-parlar.de/.../ (Erişim tarihi: 27.02.2021)

Aktaş, K., Kılıç, P. 2013. Sebze Soya Filizi Yetiştiriciliğinde (Glycine Max L.) Tuz Uygulamalarının Tohum Çimlenmesi ve Filiz Kalitesi Üzerine Etkileri, YYÜ TAR BİL DERG , 23(3): 236-241. https://dergipark.org.tr/tr/download/article-file/204709. (Erişim tarihi: 27.01.2021)

Awang, Y. B.; Atherton, J. G.; Taylor, A. J. 1993. Salinity effects on strawberry plants grown in rockwool. II. Fruit quality. J. Hortic. Sci. 68, 791-795. doi.org/10.1080/00221589.1993.11516414

Büyük, İ., Soydam-Aydın, S., Aras, S. 2012. Bitkilerin Stres Koşullarına Verdiği Moleküler Cevaplar, Türk Hijyen ve Deneysel Biyoloji Dergisi, 69(2): 97 - 110. DOI: 10.5505/TurkHijyen.2012.40316

D’Anna, F. D.; Incalcaterra, G.; Moncada, A.; Miceli, A. 2003. Effects of different electrical conductivity levelson strawberry grown in soilless culture. Acta Hortic. , 609, 355-360. doi.org/10.17660/ActaHortic.2003.609.53

Epstein E., Norlyn J.D., Rush D.W., Kingsbury R.W., Kelly C.B., Cunningham G.A., Wrona A. 1980. Saline culture of crops: A Genetic Approach, Sci., 210: 399-945. DOI: 10.1126/science.210.4468.399

Gerdakaneh, M., Mozafari, A., Khalighi, A., Mardah, A. 2010. The effects of exogenous proline and osmotic stress on morpho-biochemical parameters of strawberry callus, African Journal of Biotechnology Vol. 9(25), pp. 37753779, 21. DOI: 10.5897/AJB09.1828

Greenway H., Munns R., 1980. Mechanism of salt tolerance in non-halophytes, Annu. Rev. Plant Physiol. 31 (1980) 149-190. doi.org/10.1146/annurev.pp.31.060180.001053

Hoffman, GJ. 1981. Alleviating salinity stress. In Modifying the Root Environment to Reduce Crop Stress, Chap. 9, eds. Arkin GF, Taylor HM, pp. 305-343. American Society of Agricultural Engineers, St. Joseph, MI.

Keutgen, A. J.; Keutgen, N. 2003. Influence of $\mathrm{NaCl}$ salinity stress on fruit quality in strawberry. Acta Hortic. (ISHS), 609, 155- 157. doi.org/10.17660/ActaHortic.2003.609.20

Keutgen, A.J., Pawelzik, E. 2007. Modifications of Strawberry Fruit Antioxidant Pools and Fruit Quality under $\mathrm{NaCl}$ Stress. Journal Of Agricultural and Food Chemistry, 55, 4066 $\square$ 4072. DOI: 10.1021/jf070010k

Kuşvuran, Ş. 2010. Kavunlarda Kuraklık ve Tuzluluğa Toleransın Fizyolojik Mekanizmaları Arasındaki Bağlantılar (Çukurova Üniversitesi, Fen Bilimleri Enstitüsü, Bahçe Bitkileri Anabilim Dalı, Doktora Tezi, Mart, 2010, 355s.

Levitt J., Salt and ion stress, in: Levitt J. 1980. (Ed.), Responses of plants to environmental stresses, Vol. II, Water radiation, salt and others stresses, Acad. Press, New York, USA, 1980, pp. 365-488.

Martinez Barroso, MC., Alvarez, CE. 1997. Toxicity symptoms and tolerance of strawberry to salinity in the irrigation water. Sci. Hortic., 71: 177-188. Ashton Research Sta., University of Bristol, UK.

Murashige, T. and F. Skoog. 1962. A revised medium for rapid growth and bioassays with tobacco tissue culture. Physiol. Plant. 15:473- 497.

Saied, A. S.; Keutgen, A. J.; Noga, G. 2005. The influence of $\mathrm{NaCl}$ salinity on growth, yield and fruit quality of strawberry cvs. 'Elsanta' and 'Korona'. Sci. Hortic. 103, 289-303. DOI: 10.1016/j.scienta.2004.06.015

Torun, A.A., Kaçar-Aka, Y., Kıllı, O., Erdem, H., Yardım, P., Serçe, S., İnan, S. 2007. Bazı Fragarıa Chıloensıs Genotiplerinin Değişik Nacl Konsantrasyonlarına In Vitro Çoğaltma Sırasındaki Tepkileri, Batı Akdeniz Tarımsal Araştırma Enstitüsü Derim Dergisi, 24(2):27-33, ISSN 1300-3496.

Turhan, E., Eriş, A. 2007. Growth and Stomatal Behaviour of Two Strawberry Cultivars under Long-Term Salinity Stress. Turk J Agric For 55-61.

Üzal, Ö., Yıldız, K. 2014. Bazı Çilek (Fragaria x ananassa L.) Çeşitlerinin Tuz Stresine Tepkileri, Yüzüncü Yıl Üniversitesi, Tarım Bilgileri Dergisi, 24 (2): 159- 167. doi.org/10.29133/yyutbd.235929

Yavuzlar, E.E., Adak, N. 2019. Farklı Çilek Genotiplerinin In vitro Tuzluluk Tolerans Düzeyleri Üzerine Araştırmalar, Hasat Uluslararası Tarım Ve Orman Kongresi , Birinci Basım, ISBN: 978 - 605 - 7602 - 92 - 3, 65, 21-23 Haziran, Ankara.

Yllmaz, H., Kina, A. 2008. The influence of $\mathrm{NaCl}$ salinity on some vegetative and chemical changes of strawberries (Fragaria $\mathrm{x}$ ananassa L.), African Journal of Biotechnology Vol. 7 (18), pp. 3299-3305. doi.org/10.1080/01904167.2013.766210

Zhao, X., Li, G., Li, L.J., Hu, P.P., Zhou H. C. 2017. Acta Hortic. 1156. ISHS. Proc. VIII International Strawberry Symposium. doi.org/:10.17660/ActaHortic.2017.1156.130. 